\title{
The structure of the $\mathrm{Ca}^{2+}$-binding, glycosylated F-spondin domain of F-spondin - A C2-domain variant in an extracellular matrix protein
}

\author{
Kemin $\operatorname{Tan}^{1 *}$ and Jack Lawler ${ }^{2^{*}}$
}

\begin{abstract}
Background: F-spondin is a multi-domain extracellular matrix (ECM) protein and a contact-repellent molecule that directs axon outgrowth and cell migration during development. The reelin_N domain and the F-spondin domain (FS domain) comprise a proteolytic fragment that interacts with the cell membrane and guides the projection of commissural axons to floor plate. The FS domain is found in F-spondins, mindins, M-spondin and amphiF-spondin.

Results: We present the crystal structure of human F-spondin FS domain at $1.95 \AA$ resolution. The structure reveals a $\mathrm{Ca}^{2+}$-binding $\mathrm{C} 2$ domain variant with an 8-stranded antiparallel $\beta$-sandwich fold. Though the primary sequences of the FS domains of F-spondin and mindin are less than 36\% identical, their overall structures are very similar. The unique feature of F-spondin FS domain is the presence of three disulfide bonds associated with the $\mathrm{N}$ - and Ctermini of the domain and a highly conserved N-linked glycosylation site. The integrin-binding motif found in mindin is not conserved in the F-spondin FS domain.

Conclusion: The structure of the F-spondin FS domain completes the structural studies of the multiple-domain ECM molecule. The homology of its core structure to a common $\mathrm{Ca}^{2+}$ - and lipid-binding C2 domain suggests that the F-spondin FS domain may be responsible for part of the membrane targeting of F-spondin in its regulation of axon development. The structural properties of the FS domain revealed in this study pave the way for further exploration into the functions of F-spondin.
\end{abstract}

\section{Background}

F-spondin was initially identified in the rat embryo floor plate [1], a ventralizing structure implicated in the control of neural cell patterning and axon growth in the developing vertebrate nervous system. The expression level of F-spondin is high in the floor plate at the time of axon extension [1]. Further studies have found that F-spondin plays an important role in the outgrowth of sensory [1], commissural [2] and hippocampal [3] neurons during development as well as in the migration of distinct somite domains to neural crest [4]. F-spondin is an extracellular matrix (ECM) protein with multiple domains, including an $\mathrm{N}$-terminal domain (reelin_N

\footnotetext{
* Correspondence: ktan@anl.gov; jlawler@bidmc.harvard.edu 'Midwest Center for Structural Genomics and Structural Biology Center, Biosciences Division, Argonne National Laboratory, Argonne, IL 60439, USA ${ }^{2}$ Division of Experimental Pathology, Department of Pathology, Beth Israel Deaconess Medical Center and Harvard Medical School, Boston, MA 02215, USA

Full list of author information is available at the end of the article
}

domain) [5], an F-spondin (FS) domain and six thrombospondin type 1 repeats (TSRs) (Figure 1A). F-spondin, which is secreted by cells within the floor plate, is proteolytically processed into fragments that differentially bind to the floor plate cells or the basement membrane [6]. The portion that binds to the floor plate cells acts as a short-range repellent of commissural axons and prevents their migration into the floor plate. Other portions of F-spondin that includes the FS domain accumulate at the basement membrane and support growth cone migration [6]. The proteolysis of F-spondin and the coordinated interaction of the different fragments with the membrane of floor plate and the basement membrane provide a combinatorial guidance signal for commissural axons that cross the midline [6]. F-spondin is also highly up-regulated in injured peripheral nerves and it promotes outgrowth of sensory neurons [2]. An antibody against the FS domain blocks neurite outgrowth, indicating the FS domain plays an active role in

\section{Ciomed Central}




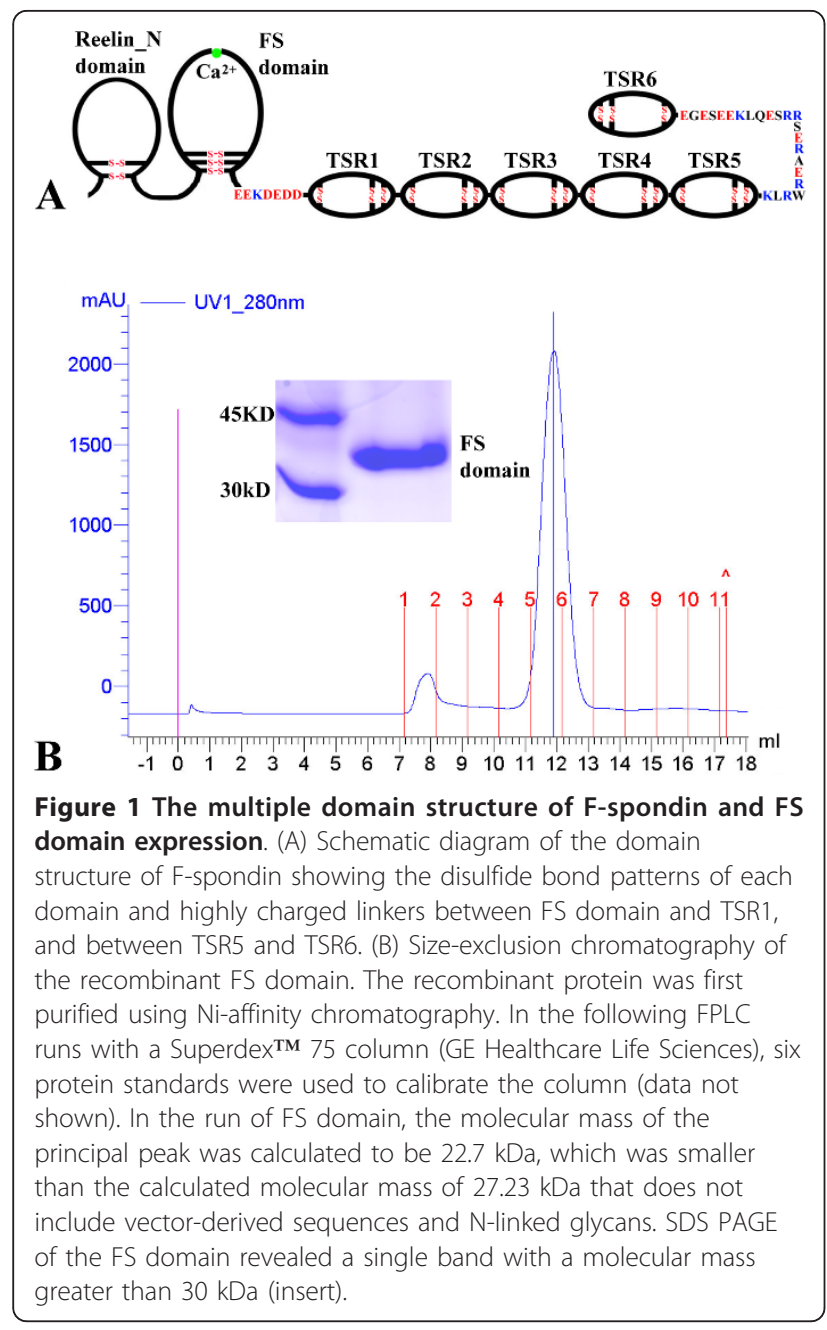

axon regeneration [2]. This observation is largely in agreement with the fact that an F-spondin fragment that lacks the TSRs is sufficient to promote neuronal differentiation [7].

The expression of F-spondin indicates that it also functions outside the nervous system. F-spondin is expressed in various organs including the ovary, lung, kidney, small intestine, prostate [8] and testis [9]. Human and bovine F-spondins, initially called vascular smooth muscle cell (SMC) growth-promoting factor (VSGP), were first cloned from ovarian cDNA libraries, and bovine F-spondin was purified from adult bovine ovarian follicular fluid [8]. F-spondin may be a major factor for SMC proliferation in the ovary. In vitro experiments suggested that F-spondin may also contribute to the inhibition of angiogenesis via the functional blockade of endothelial integrin $\alpha v \beta 3$, which plays important roles in angiogenesis [10]. It has been recently shown that F-spondin is a promoter for cementoblastic differentiation [11]. The molecule is up-regulated in osteoarthritis, promoting prostaglandin production, collagen degradation and proteoglycan synthesis reduction, probably via the activation of latent TGF- $\beta$ [12].

The first identification of ligands for F-spondin came from the studies of the pathogenesis of Alzheimer's disease $[13,14]$. Amyloid precursor protein (APP) is a type I membrane protein. Its extracellular domain is initially cleaved by $\alpha$ - or $\beta$-secretases and subsequently by $\gamma$ secretase to secrete small peptides including $A \beta 40$ and $\mathrm{A} \beta 42$, which are the primary components of the amyloid- $\beta$ fibrils found in Alzheimer's disease. F-spondin interacts with the extracellular domain of APP, blocks APP cleavage by $\beta$-secretases, and eventually inhibits the production of the $A \beta$ peptides by $\gamma$-secretase [13,14]. A working model suggested that F-spondin forms a heterotrimer assembly on the membrane with APP and apolipoprotein E receptor 2 (apoEr2) in which the reelin_N domain and the FS domain interact with APP and TSRs interact with apoEr2 [14,15].

Recently, the structure of mindin FS domain has been reported [16]. Mindin is a member of the Mindin/Fspondin family $[3,17]$ and an integrin-binding and pattern-recognition molecule for microbial pathgens $[16,18,19]$. In this paper, we present the crystal structure of human F-spondin FS domain. With the structures of the N-terminal (reelin_N) domain [5,20] and TSRs [21] of F-spondin characterized, the structure of FS-domain is the last to be determined and studied.

\section{Results and Discussion}

\section{Overview of FS domain structure}

The core of the FS domain has an 8 -stranded $\beta$-sandwich fold, with strands $\beta 4, \beta 1, \beta 8$, and $\beta 7$ forming one $\beta$-sheet and strands $\beta 3, \beta 2, \beta 5$ and $\beta 6$ forming the other sheet (Figure 2). The topology represents one of two types of $\mathrm{C} 2$ domain $\beta$-sandwich folds [22]. The first major variation of the FS domain, as compared to a common $\mathrm{C} 2$ domain, is its long linker (38 amino acids) between $\beta 2$ and $\beta 3$ strands, which actually forms two anti-parallel $\alpha$-helices, packed against the $\beta 3 / \beta 2 / \beta 5 / \beta 6$ sheet. The second variation is its long linker (51 amino acids) between the $\beta 7$ and $\beta 8$ strands. The linker first crosses over to the $\beta 3 / \beta 2 / \beta 5 / \beta 6$ sheet and forms a short strand, $\beta 7^{\prime}$ (W353D354) that is anti-parallel to the edge strand, $\beta 6$ (Figure 2 and 3). It then runs above the $\beta 5$ $\beta 6$ loop and turns back at Y363. The linker forms a second short strand, $\beta 7$ " (R377-P378), by $\beta 7$ '. The addition of the two short strands is an expansion of the $\beta 3 / \beta 2$ / $\beta 5 / \beta 6$ sheet to a 6 -stranded sheet. Additionally, a part of the loop between $\beta 2$ and $\alpha 1$ (G249-G250) runs in an anti-parallel fashion by the $\beta 7$ " strand, forming two mainchain-mainchain hydrogen bonds with the residue I376 right before $\beta 7$ ". These two interactions (G249 N- 


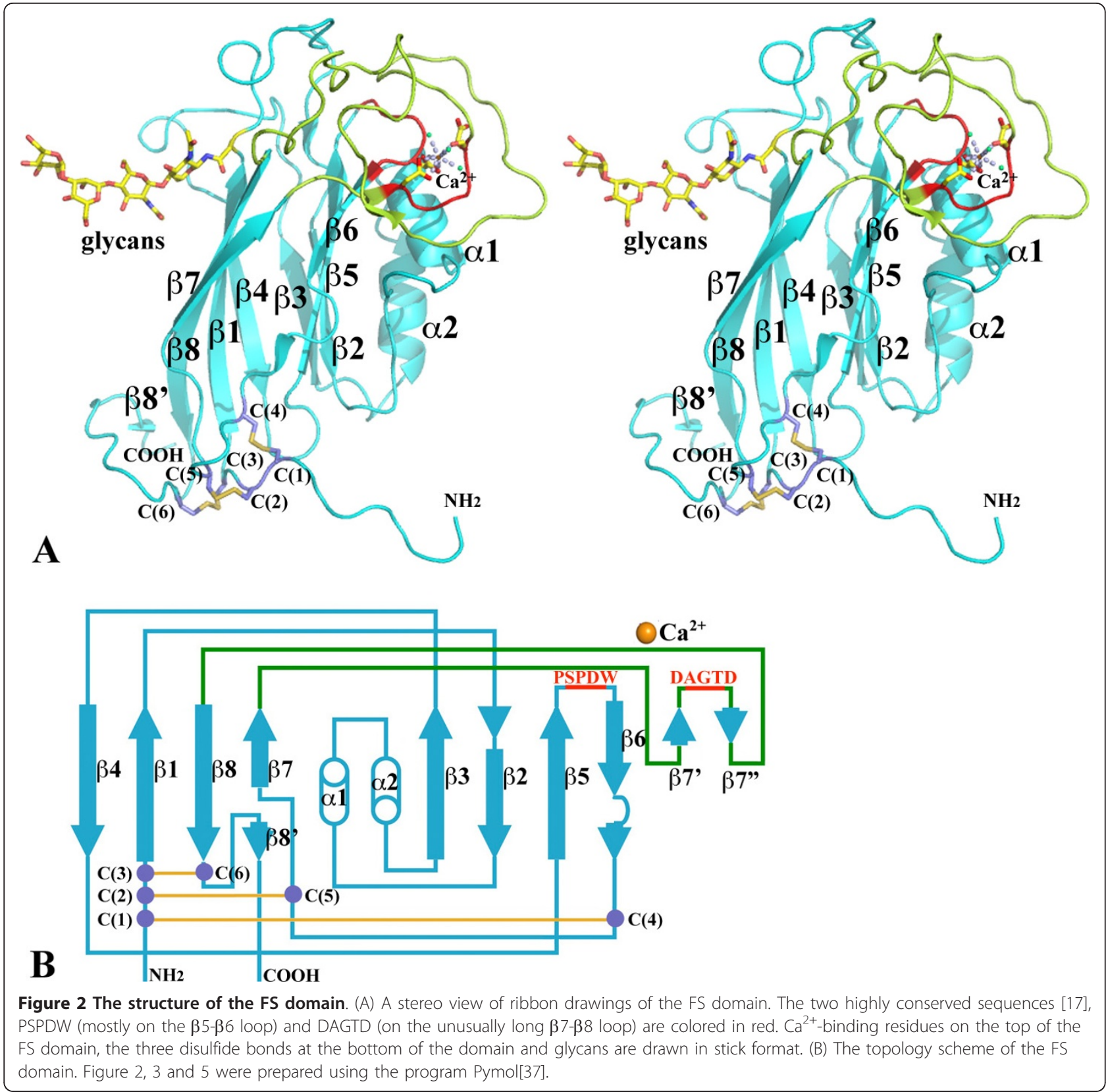

I374 $\mathrm{O}$ and G250 O-I374 N) do not define another $\beta$ strand.

The residues contributing to the hydrophobic core of the FS domain are A205, Y207, L209 and F211 of the $\beta 1$ strand, I234 of the $\beta 2$ strand, F305 and V307 of the $\beta 4$ strand, M314 and F316 of the $\beta 5$ strand, as well as A 401, V403 and I405 of the $\beta 8$ strand (Figure 4). Based on the sequence conservation of these residues among FS domains of F-spondins, mindins, $\mathrm{M}$-spondin as well as AmphiF-spondin, we predict that a $\mathrm{C} 2$ domain core structure should be conserved in these proteins.

\section{Disulfide bond pattern}

The three consecutive cysteines (C199, C200 and C202) before the $\beta 1$ strands form three disulfide bonds with C336 and C340 from the $\beta 6-\beta 7$ loop, and C415 after the $\beta 8$ strand at the $C$-terminal region, respectively (Figure 2). None of these disulfide bonds is located within the core of the $\beta$-sandwich domain. They are all at the bottom of the FS domain and are associated with $\mathrm{N}$ - and $\mathrm{C}$-termini, especially the $\mathrm{N}$-terminus, where they seem to help define and stabilize the globular FS domain (Figure 2). The construct for protein expression begins from V191. In the electron density maps, D198 is the 


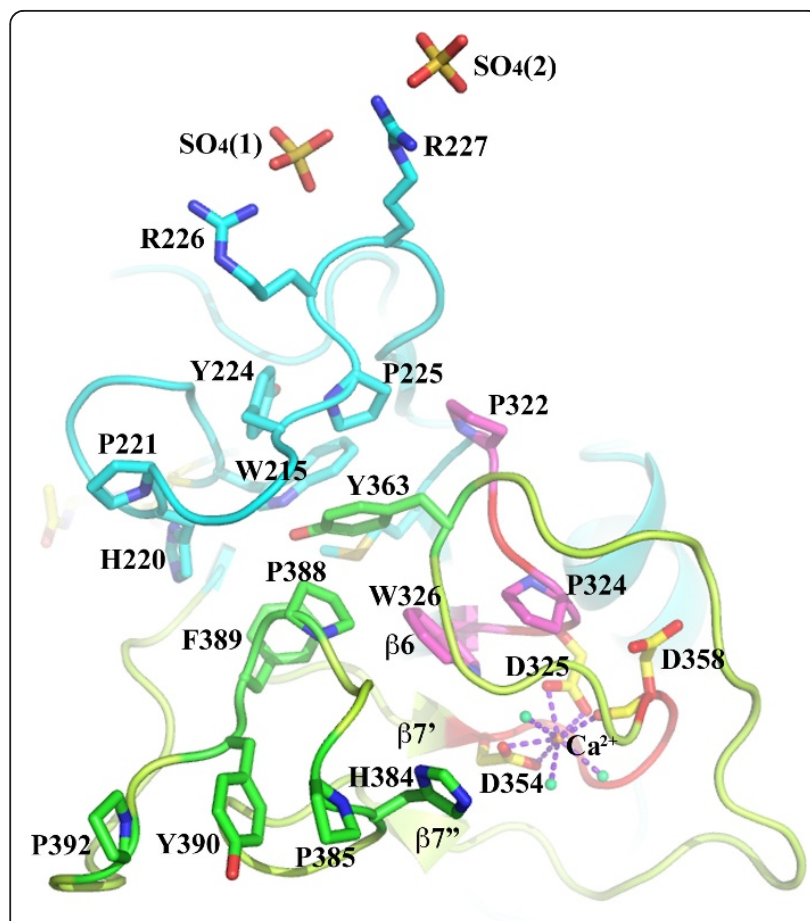

Figure 3 The top of the FS domain. Besides $\mathrm{Ca}^{2+}$-binding site, two of three $\mathrm{SO}_{4}{ }^{2-}$ groups (from crystallization buffer) identified in the structure are associated with R226 and R227 on one side of the top of the FS domain. The top of the FS domain is also rich in aromatic residues and prolines. The $\beta 7-\beta 8$ loop covers most the of FS domain on one side. When it turns at $Y 363$, the sidechain of Y363 dips into a pocket containing aromatic residues and prolines, including P388 and F389. After the $\beta 7^{\prime \prime}$ short strand, four rings from H384, P385, Y390 and P392 are parallel to each other in a row. Additional aromatic residues from other loops are also found on the top of the domain, including W215, W231, P324, W326, P352, W353, Y363 and F383. All of these residues are either identical or highly conserved in the FS domains of other proteins (Figure 4). The role of these aromatic residues is unknown.

first $\mathrm{N}$-terminal residue visible while the other seven residues together with 6 vector-derived residues were disordered in the structure. Interestingly, after the $\beta 8$ strand, about 13 residues between $\mathrm{C} 415$ and D428 are clear in the electron density maps. Two of them, I425 and V426, form a short strand ( $\left.\beta 8^{\prime}\right)$ parallel to $\beta 8$, providing structural stability to the $\mathrm{C}$-terminal loop region after C415.

There is a noticeable difference in the number of disulfide bonds in the FS domains of F-spondin and mindin. Early understanding of the FS domain structure was based on two very conserved sequence repeats, fs 1 and fs2, which were suggested to represent two individual domains [17]. However, an analysis based on the number of cysteine residues and their distribution actually suggested a disulfide bond pattern that was not in agreement with the early prediction. In the F-spondin FS domain, there are six cysteines, designated $\mathrm{C}(1)$ to $\mathrm{C}$
(6). $C(1-3)$ are in the fs 1 repeat, $C(4-5)$ are in the fs2 repeat and $C(6)$ is in a region after fs 2 . In mindin, only $C(1)$ and $C(4)$ exist, suggesting a possible disulfide bond $\mathrm{C}(1)-\mathrm{C}(4)$ linking fs1 and fs2. In AmphiF-spondin, $\mathrm{C}(2)$ and $\mathrm{C}(5)$ are both missing and are replaced by a pair of hydrogen bond forming residues, T190 and Q330 (Figure 4). This implies the second disulfide bond $C(2)-C(5)$ is also between fs 1 and fs 2 in other proteins. The remaining cysteine $(\mathrm{C}(3))$ of fs1 likely forms the third disulfide bond with $C(6)$ after fs 2 . These results are consistent with the conclusion that fs 1 and fs 2 are most likely within a single domain. The functionality and the evolution of the varied disulfide bond patterns are unknown. A phylogenetic analysis using the alignment in Figure 4 as an input suggests that FS domains of Fspondins and mindins have evolved separately from their common ancestor [23]. The result largely agrees with the observation that the numbers and the positions of the exons that cover FS domains in genomic DNAs are different between F-spondins and mindins.

\section{C-termini of FS domains}

The C-terminal region of FS domains is one of the most diversified regions in the amino acid sequences (Figure 4). The location of the C-terminus of F-spondin or mindin is different according to the structures of their FS domains. In the construct of mindin [16], the C-terminus was truncated at R223, which is equivalent to E413 of F-spondin. In the structure reported here, E413 is before $\mathrm{C} 415$ and on the structured C-terminal loop between the $\beta 8$ and the $\beta 8^{\prime}$ strands. In mindin, there is no disulfide bond tethering its $\mathrm{C}$-terminal region to its $\mathrm{N}$-terminus. The end of the $\beta 8$ strand is L218 and the following residue $\mathrm{R} 219$ starts to peel off from the mindin FS domain (Figure 5A), resulting in disordering of most of the other $\mathrm{C}$-terminal residues of the construct [16]. In F-spondin, residue A409, the equivalent of $\mathrm{R} 219$ in mindin, is the third residue from the end of the $\beta 8$ strand (Figure 4 ). The $\mathrm{C}$-terminal loop region observed in F-spondin seemingly extends the C-termini of the FS domain to at least V426 (Figure 2). We note that exon 10 of human F-spondin genomic DNA encodes the $\mathrm{C}$-terminal region of the FS domain, from G412 to E436. It is possible that the C-terminus of Fspondin FS domain extends much beyond the disulfide bond formed by C415. However, we can't exclude the possibility that the $\mathrm{C}$-terminal structured region (from $\mathrm{N} 416$ to V426) results from molecular packing in the crystal.

\section{$\mathrm{N}$-linked glycosylation, $\mathrm{Ca}^{2+}-$ and $\mathrm{SO}_{4}{ }^{2-}$-binding sites}

There is one N-linked glycosylation site (N214) at the end of the $\beta 1$ strand in the FS domain (Figure 2A). The common pentasaccharide core of the linked glycans is 


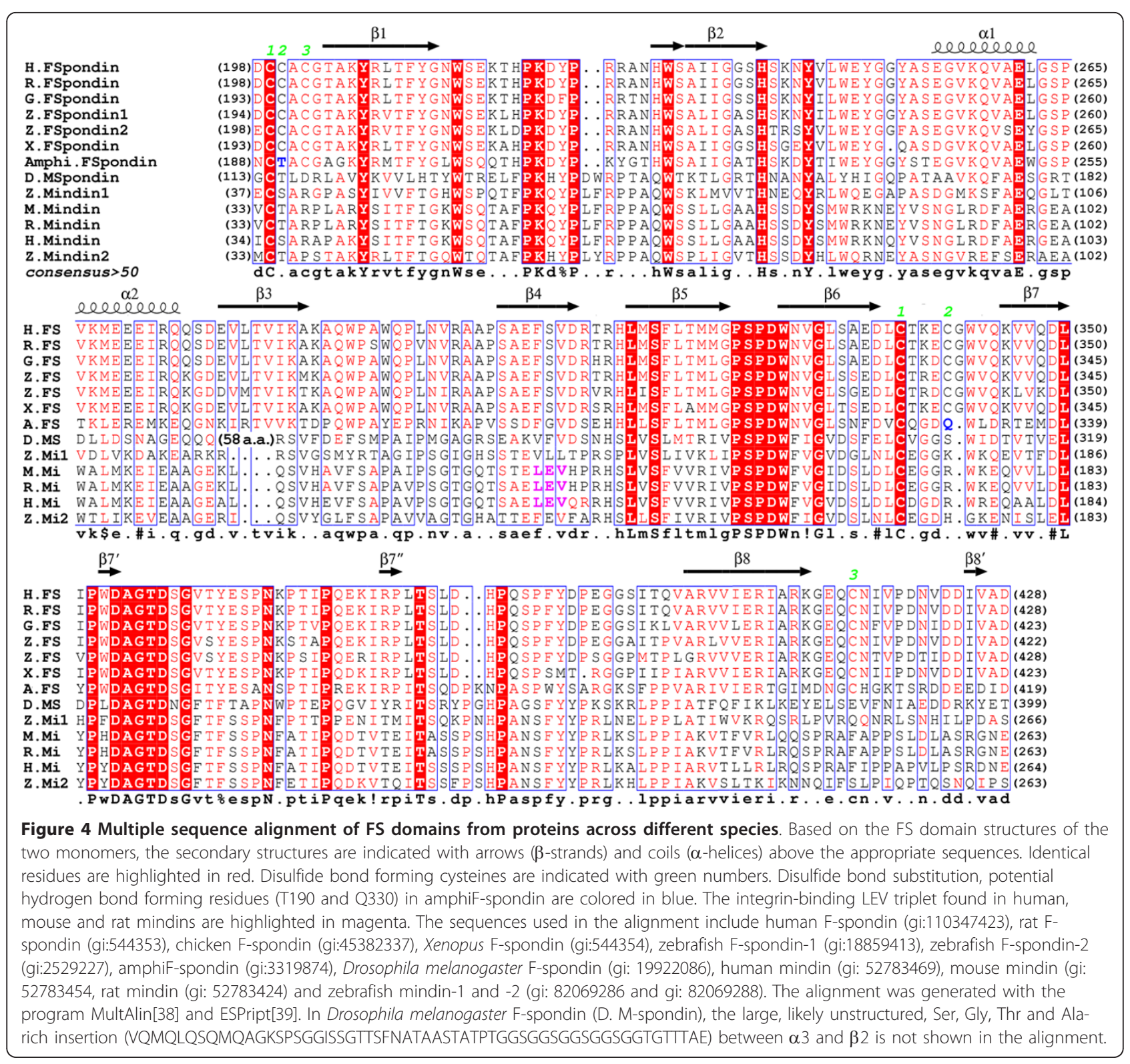

visible in the electron densities. Two branched mannose residues were not built in the final model due to their weak densities. Like other proteins that we have expressed in Drosophila S2, the N-linked glycans are not fully processed $[5,24]$. The post-translational modification in the FS domain is conserved only in F-spondins while in mindins only zebrafish mindin-1 and -2 FS domains are glycosylated, at different sites (Figure 4).

Associated with the short strands at the top of the FS domain, there is a solvent-accessible $\mathrm{Ca}^{2+}$-binding site, formed from D325 (from $\beta 5-\beta 6$ loop), D354 (from $\beta 7$ ' short strand) and D358 (right after $\beta 7$ ' short strand). The site also contains three coordinating water molecules in an approximately octahedral coordination geometry (Figure 2 and 3). All three aspartic acids are from the two highly conserved and characteristic FS domain "repeats", P322SPDW and D354AGTD (in Fspondin) [17]. Both D325 and D354 interact with the $\mathrm{Ca}^{2+}$ ion as bidentate ligands involving both carboxyl groups with bond distances of $2.49 \AA / 2.53 \AA$ and 2.38 $\AA / 2.46 \AA$, respectively. Interestingly, D358 interacts with the $\mathrm{Ca}^{2+}$ ion with only its mainchain carbonyl group $(2.33 \AA)$ though the residue is part of a highly conserved motif. All three aspartic acids and three coordinating waters ( $2.47 \AA$ for all) are part of an extensive hydrogen bond network. The geometry of the metal-binding site, including bond distances, coordination [25] as well as the similar B-factors of the $\mathrm{Ca}^{2+}$ ion $\left(16.2 \AA^{2}\right)$ and its 
surround protein atoms $\left(\sim 15.5 \AA^{2}\right)$, support the metal ion assignment.

Three sulfate groups from the crystallization buffer that included $0.2 \mathrm{M}$ lithium sulfate monohydrate have also been identified in the structure (Figure 3). One of them is inside a pocket near the bottom of the domain (not shown in the figure). The other two sulfate groups, labeled as $\mathrm{SO}_{4}(1)$ and $\mathrm{SO}_{4}(2)$ in Figure 3, are associated with two consecutive arginines, R226 and R227, on one side of the top of the FS domain. The $\mathrm{SO}_{4}(1)$ occupies a special position with 2-fold crystallographic symmetry, and binds the residues R226 and R227, and the same residues from an adjacent, symmetry-related FS molecule.

\section{Structural homologues}

The primary sequence identity of the FS domains between F-spondin (human, a.a.198-428) and mindin (human, a.a.34-264) is $35.9 \%$. A secondary-structure matching (SSM) superposition [26] of two molecules yields a core root mean square deviation (rmsd) of 1.14 $\AA$ with 200 residues from each aligned (Figure 5A). In the alignment, there are eight gaps, all in loop regions with the major difference (an insertion of six residues in
F-spondin) occurring before the $\beta 4$-strand and creating a protrusion from the edge of the $\beta 4 / \beta 1 / \beta 8 / \beta 7$ sheet. The protrusion is accompanied by the $\mathrm{N}$-linked glycans extended from the end of the neighboring $\beta 1$-strand as described earlier.

A Dali structural homology search (http://www2.ebi.ac. $\mathrm{uk} /$ dali/) using the F-spondin FS domain found a large number of fits $(\mathrm{Z} \leq 5.8$ and rmsd $\geq 3.3 \AA)$, including the $\mathrm{N}$-terminal $\mathrm{Ca}^{2+}$-dependent lipid-binding/C2 domain of cytosolic phospholipase A2 (PDB code:1CJY) [27]. In the structural alignments of the FS domain with these $\mathrm{C} 2$ domains, only the core of the FS domain (commonly about 110-120 residues) can be superimposed, indicating that the FS domain represents a derivative of a common $\mathrm{C} 2$ domain (Figure 5B). Though helices are commonly found within the linker between two strands in C2 domain structures, the two nearly anti-parallel helices within the loop between the $\beta 2$ and $\beta 3$ strands and the unusual long loop between the $\beta 7$ and $\beta 8$ strands found in the FS domain are unique to FS domains only.

\section{Implication of Potential Interactions}

Membrane targeting is an important part of axon guidance of the proteolytic fragment of F-spondin that

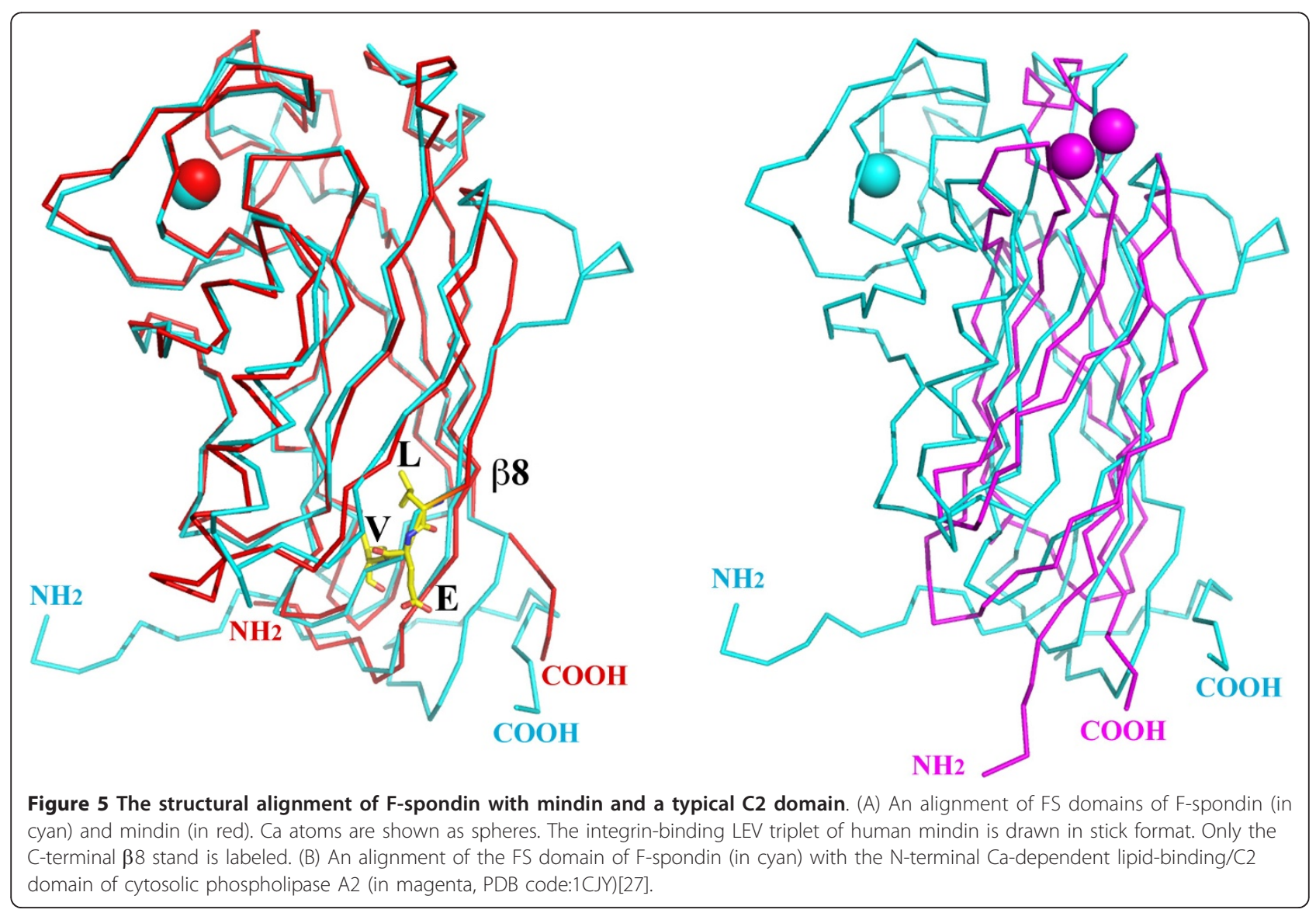


includes the FS domain. The unexpected identification of a C2 domain homology with the FS domain and the presence of $\mathrm{Ca}^{2+}$ - and $\mathrm{SO}_{4}{ }^{2-}$-binding sites implies potential roles of this domain in the interaction of F-spondin with membrane and/or membrane associated molecules.

The $\mathrm{C} 2$ domain is the second most abundant lipid binding domain behind the pleckstrin homology $(\mathrm{PH})$ domain $[28,29]$. Though the $\mathrm{C} 2$ domain can fold individually with a highly conserved common $\beta$-sandwich core, it seems to be a modular domain that is found in a large number of multiple domain proteins involved in signal transduction or membrane trafficking. Most of the $\mathrm{C} 2$ domain-containing molecules that have been studied to date are either soluble proteins or membrane proteins. The FS domain structures of mindin and Fspondin represent the first examples of structures from ECM proteins that contain a $\mathrm{C} 2$-domain or rather a $\mathrm{C} 2$ domain derivative. The individual $\mathrm{C} 2$ domains commonly participate in $\mathrm{Ca}^{2+}$-dependent membrane binding in $\mathrm{Ca}^{2+}$-mediated cell processes.

In most cases, the membrane-binding and/or lipid binding of $\mathrm{C} 2$ domains is dependent on the $\mathrm{Ca}^{2+}$-binding site(s), though the number of $\mathrm{Ca}^{2+}$ binding-sites and their positions at the top of the domains are variable [28]. $\mathrm{Ca}^{2+}$ ions can (1) function as an electrostatic switch for favorable ionic interaction with the anionic membrane, (2) form a bridge between the C2 domain and anionic phospholipids, or (3) induce conformational changes that lead to protein-membrane interactions [28]. The exact methods for the $\mathrm{C} 2$ domain interaction with membranes, including lipid selectivity, may be dependent on the number of $\mathrm{Ca}^{2+}$-binding sites and the conformation of each $\mathrm{Ca}^{2+}$-binding site. Additionally, protein-membrane associations mediated by divalent metals, especially $\mathrm{Ca}^{2+}$ ions, have been reported in many other proteins, including vitamin-K-dependent proteins, annexins and pentraxins [30].

The presence of a sulfate group from crystallization buffer in a crystal structure could be an indicator of a binding site of an anionic group of a potential ligand, such as heparin (with sulfate group) and lipid (with phosphate head group). The arginines, R226 and R227, on one side of the top of the FS domain could contribute to a binding site for the phosphate head group of a lipid. It is interesting that R226 is conserved between Fspondins and mindins while R227 in mindins is replaced by a proline (Figure 4). Heparin-binding has been demonstrated for F-spondin's N-terminal reelin_N domain [5], which is adjacent to the FS domain (Figure 1A). The potential for the two consecutive arginines R226 and R227 of the FS domain to bind heparin in synergy with the reelin_N domain remains to be explored. The presence of two sulfate groups, especially $\mathrm{SO}_{4}(1)$ at a crystallographic special position, could be an artifact of molecular packing. The heparin-binding, or more generally glycosaminoglycan (GAG)-binding, implies another potential pathway for targeting the membrane through the interaction with membraneassociated GAGs such as those from transmembrane proteoglycans.

\section{Conclusions}

The structure of F-spondin FS domain, together with mindin FS domain, represents the first examples of $\mathrm{C} 2$ domain-like structures in ECM proteins. Although the two FS domains have similar overall structures, they have evolved separately from their common ancestor. The integrin-binding motif found in mindin is not conserved in the F-spondin FS domain. The F-spondin FS domain is unique with a conserved $\mathrm{N}$-glycosylation site and three disulfide bonds, which may play critical roles in protein folding and stability as well as defining domain boundaries. The homology of its core structure to a common $\mathrm{Ca}^{2+}$ - and lipid-binding $\mathrm{C} 2$ domain suggests that the F-spondin FS domain may be responsible for part of the membrane targeting of F-spondin in its regulation of axon development. The structure of the Fspondin FS domain completes the structural studies of the multiple domain ECM molecule and its properties revealed in this study pave the way for further exploration into the functions of F-spondin.

\section{Methods}

\section{Preparation of the Recombinant FS domain}

A cDNA pool was prepared from a mixture of human spleen, placenta and liver poly (A)+ RNA (Stratagene, La Jolla, CA) using a reverse transcription kit (Gibco-BRL, Gaithersburg, MD). A recombinant version of the human F-spondin FS domain (amino acids V191-K434) was prepared by PCR using the cDNA pool as the template. The FS domain was prepared using the forward primer fs102f (5'-GAT GAT CCC GGG GTG ACT GAC AAA CCC ATC-3') and the reverse primer fs104r (5'-ATG ATG ACC GGT TTT CTC TTC TGG AGC CAG-3'). The PCR products were sequenced and cloned between the SmaI and the AgeI sites of the vector pMT/ BiP V5-HisA (Invitrogen, Carlsbad, CA) for expression in Drosophila Schneider 2 (S2) cell. The recombinant proteins include the vector-derived sequence RSPWPG at the $\mathrm{N}$-terminal and the sequence TGHHHHHH at the C-terminal.

The vector transfection and cells selection were performed following the protocol from Invitrogen, catalog no. R690-07. The methods for FS domain expression and purification were described previously [31]. The protein was further purified by FPLC in buffer containing $200 \mathrm{mM} \mathrm{NaCl}$ and $20 \mathrm{mM}$ HEPES at $\mathrm{pH} 7.8$ with sodium as the counter ion. The apparent molecular 
Table 1 Crystallographic Statistics

\begin{tabular}{ll}
\hline Data Collection & Native \\
\hline Space group & P622 \\
\hline Unit Cell $(\AA)$ & $\begin{array}{l}a=b=120.24, \\
C=86.36\end{array}$ \\
\hline MW Da (residue) & $27230(244)^{1}$ \\
\hline Mol (AU) & 1 \\
\hline Wavelength ( $\AA$ ) & 0.97940 \\
\hline Resolution $(\AA)$ & 1.95 \\
\hline Number of unique reflections & 27486 \\
\hline Redundancy & $10.1(6.4)^{2}$ \\
\hline Completeness (\%) & $99.9(100.0)^{2}$ \\
\hline Rmerge $(\%)$ & $12.6(64.6)^{2}$ \\
\hline I/ $\sigma(I)$ & $23.4(3.4)^{2}$
\end{tabular}

\begin{tabular}{ll}
\hline Structural Refinement & \\
\hline Resolution ( $\AA$ ) & $1.95-33.5$ \\
\hline Reflections (work/test) & $25965 / 1374$ \\
\hline$R_{\text {crysta/ } / \text { free }}(\%)$ & $18.0 / 21.4$ \\
\hline $\begin{array}{ll}\text { Rms deviation from ideal geometry Bond length } \\
(\AA) / \text { angle }\left(^{\circ}\right)\end{array}$ & $0.009 / 1.135$ \\
\hline No. of atoms (Protein/HETATM) & $1911 / 402$ \\
\hline Mean B-value $\left(\AA^{2}\right)$ (mainchain/sidechain) & $19.90 / 20.70$ \\
\hline Ramachandran analysis (\%) $)^{3}$ Residues in favored & $97.10 /$ \\
regions/in allowed regions. & 100 \\
\hline Protein Geometry MolProbity score & 0.79 \\
\hline
\end{tabular}

${ }^{1}$ Not including cloning artifact and His tag.

2 (Last resolution bin, 1.95-2.00 ̊̊).

${ }^{3}$ From MolProbity[36].

weight of the eluted FS domain was estimated to be 22.7 $\mathrm{kDa}$ based on the calibration of the column with known proteins, indicating the domain exists as a monomer in solution (Figure 1B).

\section{Crystallization and X-ray Diffraction Data Collection}

The purified protein was concentrated to about $30 \mathrm{mg} /$ $\mathrm{ml}$. The crystallization was carried out with sitting drop vapor diffusion technique. Protein crystals grew from the buffer containing $0.2 \mathrm{M}$ lithium sulfate monohydrate, 25\% (w/v) PEG 3350 and 0.1 M HEPES at pH 7.5. The crystals had a hexagonal form with a dimension of about $60 \mu \mathrm{m}$ on edge. The crystals were then treated with a cryoprotectant ( $10 \%$ glycerol in crystallization buffer) and flash frozen in liquid nitrogen.

One X-ray diffraction data set was collected from a frozen crystal at $100 \mathrm{~K}$ at the 19ID beamline of the Structure Biology Center at the Advanced Photon Source, Argonne National Laboratory. The data set was processed using the program suite HKL3000 [32] (Table 1). An X-ray fluorescence spectrum of the crystal was measured with the primary beam energy of $12.659 \mathrm{keV}$.
Only two peaks, from the primary beam and Compton scattering, respectively, were recorded (data not shown).

The F-spondin FS domain structure was determined with molecular replacement method using the program MolRep [33]. One monomer from the mindin FS domain structure (PDB code:3D34) was used as a search template. After sequence substitution and manual model building using the program Coot [34], structural refinement was performed using the program Refmac [35] (Table 1). The final model includes residues from T192 to D428, N-linked glycans (up to the first mannose moiety) attached to the residue $\mathrm{N} 214$, one $\mathrm{Ca}^{2+}$ ion, three sulfate groups from crystallization buffer and 344 water molecules. The quality of the structure was validated with MolProbity [36] (Table 1).

The coordinates and structure factors of the human Fspondin FS domain have been deposited in the Protein Data Bank with accession code 3Q13.

\section{Acknowledgements}

This work was support by a grant (HL49081) from the National Heart, Lung and Blood Institute of the National Institutes of Health. The authors wish to thank Mark Duquette for technical assistance, Gekleng Chhor for proofreading, Drs. Hui Lu and Wonhwa Cho of University of Illinois at Chicago for helpful discussion and Drs. Frank Rotella and Marianne Schiffer of Argonne National Laboratory for critical reading of the manuscript.

\section{Author details}

${ }^{1}$ Midwest Center for Structural Genomics and Structural Biology Center, Biosciences Division, Argonne National Laboratory, Argonne, IL 60439, USA. ${ }^{2}$ Division of Experimental Pathology, Department of Pathology, Beth Israel Deaconess Medical Center and Harvard Medical School, Boston, MA 02215, USA.

\section{Authors' contributions}

$K T$ conceived of the study and carried out cloning, cell culture, protein purification and crystallization, X-ray diffraction data collection and structural determination, structural analysis and manuscript preparation. $J$ participated in the study design and coordination, sequence analysis and construct design, structural interpretation and manuscript preparation. All authors read and approved the final manuscript.

Received: 3 March 2011 Accepted: 10 May 2011 Published: 10 May 2011

\section{References}

1. Klar A, Baldassare M, Jessell TM: F-spondin: a gene expressed at high levels in the floor plate encodes a secreted protein that promotes neural cell adhesion and neurite extension. Cell 1992, 69(1):95-110.

2. Burstyn-Cohen T, Tzarfaty V, Frumkin A, Feinstein Y, Stoeckli E, Klar A: FSpondin is required for accurate pathfinding of commissural axons at the floor plate. Neuron 1999, 23(2):233-246.

3. Feinstein $Y$, Borrell V, Garcia C, Burstyn-Cohen T, Tzarfaty V, Frumkin A, Nose A, Okamoto $H$, Higashijima S, Soriano $E$, et al: F-spondin and mindin: two structurally and functionally related genes expressed in the hippocampus that promote outgrowth of embryonic hippocampal neurons. Development (Cambridge, England) 1999, 126(16):3637-3648.

4. Debby-Brafman A, Burstyn-Cohen T, Klar A, Kalcheim C: F-Spondin, expressed in somite regions avoided by neural crest cells, mediates inhibition of distinct somite domains to neural crest migration. Neuron 1999, 22(3):475-488.

5. Tan K, Duquette M, Liu JH, Lawler J, Wang JH: The crystal structure of the heparin-binding reelin- $\mathrm{N}$ domain of $\mathrm{f}$-spondin. Journal of molecular biology 2008, 381(5):1213-1223. 
6. Zisman S, Marom K, Avraham O, Rinsky-Halivni L, Gai U, Kligun G, TzarfatyMajar V, Suzuki T, Klar A: Proteolysis and membrane capture of F-spondin generates combinatorial guidance cues from a single molecule. The Journal of cell biology 2007, 178(7):1237-1249.

7. Schubert D, Klar A, Park M, Dargusch R, Fischer WH: F-spondin promotes nerve precursor differentiation. Journal of neurochemistry 2006, 96(2):444-453.

8. Miyamoto K, Morishita Y, Yamazaki M, Minamino N, Kangawa K, Matsuo H, Mizutani T, Yamada K, Minegishi T: Isolation and characterization of vascular smooth muscle cell growth promoting factor from bovine ovarian follicular fluid and its CDNA cloning from bovine and human ovary. Archives of biochemistry and biophysics 2001, 390(1):93-100.

9. Ohnuma H, Tanaka T, Yoshikawa A, Murokawa H, Minegishi K, Yamanaka R, Lizuka HY, Miyamoto M, Satoh S, Nakahira S, et al: The first large-scale nucleic acid amplification testing (NAT) of donated blood using multiplex reagent for simultaneous detection of HBV, HCV, and HIV-1 and significance of NAT for HBV. Microbiology and immunology 2001, 45(9):667-672.

10. Terai $Y$, Abe M, Miyamoto K, Koike M, Yamasaki M, Ueda M, Ueki M, Sato Y: Vascular smooth muscle cell growth-promoting factor/F-spondin inhibits angiogenesis via the blockade of integrin alphavbeta3 on vascular endothelial cells. Journal of cellular physiology 2001, 188(3):394-402.

11. Kitagawa M, Kudo Y, lizuka S, Ogawa I, Abiko Y, Miyauchi M, Takata T: Effect of F-spondin on cementoblastic differentiation of human periodontal ligament cells. Biochem Biophys Res Commun 2006, 349(3):1050-1056.

12. Attur MG, Palmer GD, Al-Mussawir HE, Dave M, Teixeira CC, Rifkin DB, Appleton CT, Beier F, Abramson SB: F-spondin, a neuroregulatory protein, is up-regulated in osteoarthritis and regulates cartilage metabolism via TGF-beta activation. Faseb J 2009, 23(1):79-89.

13. Ho A, Sèudhof TC: Binding of F-spondin to amyloid-beta precursor protein: a candidate amyloid-beta precursor protein ligand that modulates amyloid-beta precursor protein cleavage. Proceedings of the National Academy of Sciences of the United States of America 2004, 101(8):2548-2553.

14. Hoe HS, Wessner D, Beffert U, Becker AG, Matsuoka Y, Rebeck GW: Fspondin interaction with the apolipoprotein $E$ receptor ApoEr2 affects processing of amyloid precursor protein. Molecular and cellular biology 2005, 25(21):9259-9268.

15. Hoe HS, Rebeck GW: Functional interactions of APP with the apoE receptor family. Journal of neurochemistry 2008, 106(6):2263-2271.

16. Li Y, Cao C, Jia W, Yu L, Mo M, Wang Q, Huang Y, Lim JM, Ishihara M, Wells $L$, et al: Structure of the F-spondin domain of mindin, an integrin ligand and pattern recognition molecule. The EMBO journal 2009, 28(3):286-297.

17. Higashijima S, Nose A, Eguchi G, Hotta Y, Okamoto H: Mindin/F-spondin family: novel ECM proteins expressed in the zebrafish embryonic axis. Developmental biology 1997, 192(2):211-227.

18. He YW, Li H, Zhang J, Hsu CL, Lin E, Zhang N, Guo J, Forbush KA, Bevan MJ: The extracellular matrix protein mindin is a pattern-recognition molecule for microbial pathogens. Nature immunology 2004, 5(1):88-97.

19. Jia W, Li H, He YW: Pattern recognition molecule mindin promotes intranasal clearance of influenza viruses. Journal of immunology (Baltimore, Md:1950) 2008, 180(9):6255-6261.

20. Nagae M, Nishikawa K, Yasui N, Yamasaki M, Nogi T, Takagi J: Structure of the F-spondin reeler domain reveals a unique beta-sandwich fold with a deformable disulfide-bonded loop. Acta crystallographica Section D, Biological crystallography 2008, 64(Pt):1138-1145.

21. Pèaèakkèonen $K$, Tossavainen $H$, Permi $P$, Rakkolainen $H$, Rauvala $H$, Raulo $E$, Kilpelèainen I, Gèuntert P: Solution structures of the first and fourth TSR domains of F-spondin. Proteins 2006, 64(3):665-672.

22. Rizo J, Sèudhof TC: C2-domains, structure and function of a universal Ca2 +-binding domain. The Journal of biological chemistry 1998, 273(26):15879-15882

23. Dereeper A, Guignon V, Blanc G, Audic S, Buffet S, Chevenet F, Dufayard JF, Guindon S, Lefort $V$, Lescot $M$, et al: Phylogeny.fr: robust phylogenetic analysis for the non-specialist. Nucleic Acids Res 2008, , 36 Web Server: W465-469.

24. Tan K, Duquette M, Joachimiak A, Lawler J: The crystal structure of the signature domain of cartilage oligomeric matrix protein: implications for collagen, glycosaminoglycan and integrin binding. Faseb J 2009, 23(8):2490-2501.
25. Harding MM: The geometry of metal-ligand interactions relevant to proteins. Acta crystallographica Section D, Biological crystallography 1999, 55(Pt):1432-1443.

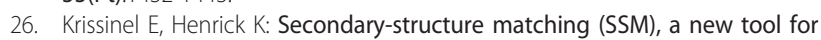
fast protein structure alignment in three dimensions. Acta crystallographica Section D, Biological crystallography 2004, 60(Pt):2256-2268.

27. Dessen A, Tang J, Schmidt H, Stahl M, Clark JD, Seehra J, Somers WS: Crystal structure of human cytosolic phospholipase $A 2$ reveals a novel topology and catalytic mechanism. Cell 1999, 97(3):349-360.

28. Cho W, Stahelin RV: Membrane binding and subcellular targeting of C2 domains. Biochimica et biophysica acta 2006, 1761(8):838-849.

29. Friedrich $R$, Yeheskel A, Ashery U: DOC2B, C2 domains, and calcium: A tale of intricate interactions. Mol Neurobiol 2010, 41(1):42-51.

30. Nelsestuen GL, Ostrowski BG: Membrane association with multiple calcium ions: vitamin-K-dependent proteins, annexins and pentraxins. Curr Opin Struct Biol 1999, 9(4):433-437.

31. Miao WM, Seng WL, Duquette M, Lawler P, Laus C, Lawler J: Thrombospondin-1 type 1 repeat recombinant proteins inhibit tumor growth through transforming growth factor-beta-dependent and -independent mechanisms. Cancer Res 2001, 61(21):7830-7839.

32. Minor W, Cymborowski M, Otwinowski Z, ChruszCZ M: HKL-3000: the integration of data reduction and structure solution-from diffraction images to an initial model in minutes. Acta crystallographica Section D, Biological crystallography 2006, 62(Pt):859-866.

33. Vagin AA, Teplyakov A: MOLREP: an automated program for molecular replacement. J Appl Crystallogr 1997, 30:1022-1025.

34. Emsley P, Cowtan K: Coot: model-building tools for molecular graphics. Acta crystallographica Section D, Biological crystallography 2004, 60(Pt):2126-2132.

35. Murshudov GN, Vagin AA, Dodson EJ: Refinement of macromolecular structures by the maximum-likelihood method. Acta crystallographica Section D, Biological crystallography 1997, 53(Pt):240-255.

36. Davis IW, Leaver-Fay A, Chen VB, Block JN, Kapral GJ, Wang X, Murray LW, Arendall WB, Snoeyink J, Richardson JS, et al: MolProbity: all-atom contacts and structure validation for proteins and nucleic acids. Nucleic Acids Res 2007, , 35 Web Server: W375-383.

37. Kraulis PJ: MOLSCRIPT: A Program to Produce Both Detailed and Schematic Plots of Protein Structures. J App/ Crystallogr 1991, 24:946-950.

38. Corpet F: Multiple sequence alignment with hierarchical clustering. Nucleic Acids Res 1988, 16(22):10881-10890.

39. Gouet P, Courcelle E, Stuart DI, Métoz F: ESPript: analysis of multiple sequence alignments in PostScript. Bioinformatics 1999, 15(4):305-308.

doi:10.1186/1472-6807-11-22

Cite this article as: Tan and Lawler: The structure of the $\mathrm{Ca}^{2+}$-binding, glycosylated F-spondin domain of F-spondin - A C2-domain variant in an extracellular matrix protein. BMC Structural Biology 2011 11:22.

\section{Submit your next manuscript to BioMed Central and take full advantage of:}

- Convenient online submission

- Thorough peer review

- No space constraints or color figure charges

- Immediate publication on acceptance

- Inclusion in PubMed, CAS, Scopus and Google Scholar

- Research which is freely available for redistribution

Submit your manuscript at www.biomedcentral.com/submit
C Biomed Central 